\title{
Intracameral Bevacizumab Versus Subconjunctival Bevacizumab in the Treatment of Neovascular Glaucoma
}

\author{
Sharjeel Sultan ${ }^{1}$, Nisar A. Siyal ${ }^{2}$, Nazish Waris ${ }^{3}$, A. Rasheed Khokar ${ }^{4}$ \\ ${ }^{1,2,4}$ Department of Ophthalmology, Dow University of Health Sciences, Civil Hospital, ${ }^{3}$ Baqai Institute of \\ Diabetology and Endocrinology, Baqai Medical University, Karachi-Pakistan
}

\begin{abstract}
Purpose: To compare the effect of intracameral Bevacizumab with sub-conjunctival Bevacizumab in the treatment of neovascular glaucoma.

Study Design: Quasi Experimental study.

Place and Duration of Study: This study was conducted at Civil Hospital Karachi, Pakistan from September 2017 to October 2018.

Material and Methods: Patients with intractable Neo-vascular glaucoma visiting the outpatient department of civil hospital, Karachi were included in the study and followed up for 8 months. Patients with sulcus or scleral fixation IOLs and those who were treated with vitreoretinal surgeries were excluded. Patients were divided into two groups. Group A included patients treated with intracameral Bevacizumab and in group B, patients treated with sub-conjunctival Bevacizumab were included. Best-corrected visual acuity (BCVA), intraocular pressure (IOP) and neovascularization of the iris (NVI) were compared between the two groups.

Results: Thirty-eight eyes were included in the study; 24 (56.7\%) right eyes and 14 (43.3\%) left eyes. Most of the patients were males with mean age of $54.53 \pm 7.2$ years. Mean total injections per eye were $3.45 \pm 1.73$ in group $A$ and $3.12 \pm 2.10$ in group B. Pre-injection BCVA (log MAR) was $0.48 \pm 0.32$ in group A and $0.34 \pm 0.32$ in group $B$. At 8 months, BCVA was $1.7 \pm 0.2$ in group $A$ and $0.48 \pm 0.34$ in group $B$ which was statistically significant. Pre-injection IOP $(\mathrm{mm} \mathrm{Hg})$ was $48.9 \pm 1.8$ in group A and $47.34 \pm 1.8$ in group B. Post-injection IOP was $28.7 \pm 0.8$ in group $A(p=0.001)$ and $34.2 \pm 3.4$ in group $B(p=0.11)$ at eight months.

Conclusion: This study demonstrates that intracameral Bevacizumab significantly improves BCVA and controls IOP in neovascular glaucoma. However, sub-conjunctival Bevacizumab significantly improves BCVA but decrease in IOP is not statistically significant.
\end{abstract}

Keywords: Neovascular glaucoma, intracameral Bevacizumab, Intraocular pressure.

How to Cite this Article: Sultan S, Siyal NA, Waris N, Khokar AR. Comparative Analysis of Intracameral Bevacizumab Vs Subconjunctival Bevacizumab in the Treatment of Neovascular Glaucoma, Pak J Ophthalmol. 2020; 36 (1): 24-28.

DOI: https://doi.org/10.36351/pjo.v36i1.993

\section{INTRODUCTION}

Neovascular glaucoma (NVG) most commonly results from conditions, which lead to retinal ischemia ${ }^{1}$.

Correspondence to: Sharjeel Sultan

Assistant Professor Ophthalmology,

Dow University of Health Sciences, Karachi, Pakistan

Email:sharj35@yahoo.com
Various diseases are involved in its occurrence including proliferative diabetic retinopathy (PDR), retinal vein occlusion, ocular ischemic syndrome, and chronic uveitis resulting in elevated intraocular pressure (IOP) and severe vision loss ${ }^{2}$. Retinal ischemia is a common factor in most of these diseases; only $3 \%$ of NVG cases are not associated with retinal ischemia $^{3}$. 
NVG can be treated by different ways. The most important strategy is to tackle the underlying disease process by retinal photocoagulation, thus reducing retinal ischemia and inhibiting the release of angiogenic factors. There are other methods as well; such as cyclo-destructive procedures or drainage devices for controlling $\mathrm{IOP}^{4}$. Anti-vascular endothelial growth factors (anti-VEGF) have some role to modify the disease course of NVG. These anti-VEGF agents have been widely used not only in NVG but also for wound healing response in traditional glaucoma surgery ${ }^{5}$. Literature shows the direct effect of these injections in inflammatory glaucoma ${ }^{6}$. Anti-vascular endothelial growth factor injections are increasingly used in the treatment of rubeosis and neovascular glaucoma. Several studies have reported regression of iris neovascularization with intravitreal and intracameral Bevacizumab ${ }^{7,8}$. The sub-conjunctival Bevacizumab approach for NVG is less commonly reported and has more often been described in treating corneal neovascularization ${ }^{9}$.

Although, pan retinal photocoagulation (PRP) effects are long lasting, but requires several weeks to show results which may lead to optic nerve damage due to elevated IOP, resulting in loss of vision ${ }^{10}$. In many studies, rapid and obvious therapeutic effects of intravitreal Bevacizumab have been reported, but little is known about the long-term efficacy of intracameral injection $^{11}$. Most patients eventually required laser or surgical procedures for IOP control, but few studies on the predictive factors have been reported for surgical treatment in spite of intraocular injection, especially intracameral injection ${ }^{2,7}$.

The purpose of this study was to assess the role of intracameral Bevacizumab and compare the results with sub-conjunctival Bevacizumab for the treatment of NVG.

\section{MATERIAL AND METHODS}

This study was conducted at Civil hospital KarachiPakistan from September 2017 to October 2018. Patients who visited outpatient department for control of NVG were recruited for this study. Following patients with NVG were included in the study; patients in whom PRP was deemed ineffective or impossible, patients who had undergone Trabeculectomy, Ahmed valve implantation, trans-scleral cyclophotocoagulation with poor control of IOP and patients with intraocular anti-VEGF injection. Patients with sulcus or scleral fixation of IOLs, and those who were treated with pars plana vitrectomy by using intraocular tamponades with silicon oil/vitreoretinal surgeries were excluded from this study.

All patients were divided into two groups; group A included patients treated with intracameral Bevacizumab and group B included patients treated with sub-conjunctival Bevacizumab. NVG was defined as an IOP of greater than $22 \mathrm{~mm} \mathrm{Hg}$, and presence of rubeotic vessels in the anterior chamber angle or corneal edema with obvious rubeosis iridis. Baseline characteristics including age, gender, laterality, causes of NVG, topical glaucoma medication and history of previous treatment were noted for each patient. Details of therapeutic interventions including intra-vitreal injection, interval between previous anti-glaucoma surgery and initial injection, complete PRP detail and laser spot area were also obtained. Pre-operative BCVA by log MAR (logarithm of the minimum angle of resolution) scale and IOP $(\mathrm{mm} \mathrm{Hg})$ were noted. Serial changes for NVI during eight months' follow-up were also noted and compared between the two groups.

Diminished vision, which varied from hand movements to $6 / 18$ was the main complaint of all the cases. In case of recurrence of NVI and IOP $>21 \mathrm{~mm}$ $\mathrm{Hg}$, despite medical and laser treatment during followup, intracameral Bevacizumab was repeated. For the prevention of further nerve damage, target IOP was estimated and set for each patient based on their initial IOP and degree of existing damage. Using 5\% povidone-iodine solution (an aseptic preparation) and topical anesthetic eye drops (proparacaine hydrochloride $0.5 \%$; Alcaine, Alcon, Fort Worth, TX, USA), Intracameral Bevacizumab $(1.25 \mathrm{mg} / \mathrm{mL}, 0.05$ $\mathrm{mL}$ ) was injected in the temporal quadrant, by a $30-$ gauge needle after paracentesis.

Weiss and Gold classification was used for NVI grading and categorized into four stages of neovascularization. Classification was based on the area of new vessels in the iris, anterior chamber angle and the location of PAS. Fine surface neovascularization of the pupillary zone of the iris involving $\leq 2$ quadrants was called grade 1 , Surface neovascularization of the pupillary zone of the iris involving $\geq 2$ quadrants was called grade 2 . In addition to the pupillary zone, neovascularization of the ciliary zone of the iris and/or ectropion uveae involving 1 to 3 quadrants called grade 3 and neovascularization of the 
ciliary zone of the iris and/or ectropion uveae involving $\geq 3$ quadrants was called grade 4 .

Data was analyzed using statistical package for social sciences (SPSS) version 20. Data was presented as mean $\pm \mathrm{SD}$ and percentage. P-value was defined significant at $>0.05$.

\section{RESULTS}

Table 1 presents the patients' baseline characteristics. There were 38 eyes included in this study, 24 (56.7\%) right eyes and $14(43.3 \%)$ left eyes. Table 2 shows the details of therapeutic interventions; intracameral Bevacizumab versus subconjunctival Bevacizumab group. In table 3, BCVA and IOP changes are shown after intracameral Bevacizumab versus subconjunctival Bevacizumab injection. Pre-injection BCVA (log MAR) was $0.48 \pm 0.32$ in group A. It improved to $0.15 \pm 0.09$ at $1^{\text {st }}$ week, $0.14 \pm 0.12$ at first month, $1.4 \pm 0.5$ at third months, $1.1 \pm 0.6$ at six months, and $1.7 \pm 0.2$ at eight months. On the other hand, pre-injection BCVA was $0.34 \pm 0.32$ in group B and post-injection improved to $0.41 \pm 0.09,0.14 \pm$ $0.12,0.31 \pm 0.9,0.98 \pm 0.1$ and $0.48 \pm 0.34$, at $1^{\text {st }}$ week, $1^{\text {st }}$ month, $3^{\text {rd }}$ month, $6^{\text {th }}$ month and $8^{\text {th }}$ month, respectively. Similarly, pre-injection IOP (mm $\mathrm{Hg}$ ) was $48.9 \pm 1.8$ in group $\mathrm{A}$ and post-injection $47.1 \pm$
2.5 at first week, $38.3 \pm 1.5$ at first month, $35.1 \pm 0.5$ at third months, $29.5 \pm 1.6$ at six months, and $28.7 \pm$ 0.8 at eight months. Pre-injection IOP was $47.34 \pm 1.8$ in group B and post-injection was $47.4 \pm 2.5,42.34 \pm$ $1.5,39.5 \pm 2.5,34.4 \pm 1.7$ and $34.2 \pm 3.4$, respectively at $1^{\text {st }}$ week, $1^{\text {st }}$ month, $3^{\text {rd }}$ month, $6^{\text {th }}$ month and $8^{\text {th }}$ month. Serial changes for NVI during eight-months follow-up are shown in table 4.

Table 1: Patients baseline characteristics.

\begin{tabular}{lr}
\hline Characteristics & Results \\
\hline No. of eyes & 38 \\
Gender & \\
Males & $16(42.6 \%)$ \\
Females & $14(57.3 \%)$ \\
Laterality & \\
Right eye & $24(56.7 \%)$ \\
Left eye & $14(43.3 \%)$ \\
Mean age of patients (years) & $54.53 \pm 7.2$ \\
Causes of neovascular glaucoma & \\
Proliferative diabetic retinopathy & $26(68.4 \%)$ \\
Central retinal vein occlusion & $5(13.2 \%)$ \\
Post vitrectomized silicon filled eyes & $7(18.4 \%)$ \\
Topical glaucoma medication & $3.85 \pm 0.34$ \\
Previous treatment & \\
Pan-retinal photocoagulation & $29(76.3 \%)$ \\
Pars plana vitrectomy & $4(10.5 \%)$ \\
Cataract surgery & $12(31.6 \%)$ \\
\hline
\end{tabular}

Data presented as mean $\pm \mathrm{SD}$ or $\mathrm{n}(\%)$

Table 2: Details of therapeutic interventions in intracameral Bevacizumab vs. sub-conjunctival Bevacizumab group.

\begin{tabular}{lccc}
\hline Parameters & Group A & Group B & P-value \\
\hline No. of eyes & $\mathbf{2 8}$ & $\mathbf{1 0}$ & $3.12 \pm 2.10$ \\
Total injections per eye & $3.45 \pm 1.73$ & $\mathrm{P}=0.43$ & $\mathrm{P}=0.001$ \\
Interval between previous surgery and first injection (in days) & $32.54 \pm 20.15$ & $29.14 \pm 28.39$ & $\mathrm{P}=0.21$ \\
Complete PRP & $8(28.6 \%)$ & $3(30.0 \%)$ & \\
Laser Photocoagulation & & & 0.001 \\
1-2 quadrant & $19(67.9 \%)$ & $7(70.0 \%)$ & 0.035 \\
3-4 quadrant & $9(32.1 \%)$ & $3(30.0 \%)$ & \\
Pre-injection Surgical treatments for NVG & & & 0.006 \\
Trabeulectomy & $15(53.6 \%)$ & $6(60.0 \%)$ & 0.04 \\
Ahmed valve implantation & $2(7.1 \%)$ & $0(0.0 \%)$ & 0.001 \\
Trans scleral cyclophotocoagulation & $11(39.3 \%)$ & $4(40.0 \%)$ & \\
\hline
\end{tabular}

Data presented as mean $\pm \mathrm{SD}$ or $\mathrm{n}(\%)$, $\mathrm{P}$-value $<0.05$ considered as significant

Table 3: Changes in BCVA and IOP after intracameral Bevacizumab and sub-conjunctival Bevacizumab injection.

\begin{tabular}{|c|c|c|c|c|c|c|c|c|}
\hline & Characteristics & $\begin{array}{c}\text { Pre- } \\
\text { operative }\end{array}$ & First Week & First Month & $\begin{array}{c}\text { Third } \\
\text { Months }\end{array}$ & $\begin{array}{c}\text { Six } \\
\text { Months }\end{array}$ & $\begin{array}{c}\text { Eight } \\
\text { Months }\end{array}$ & $\begin{array}{c}\text { P- } \\
\text { value }\end{array}$ \\
\hline Group & BCVA(log MAR) & $0.48 \pm 0.32$ & $0.15 \pm 0.09$ & $0.14 \pm 0.12$ & $1.4 \pm 0.5$ & $1.1 \pm 0.6$ & $1.7 \pm 0.2$ & 0.001 \\
\hline A & IOP $(\mathrm{mm} \mathrm{Hg})$ & $48.9 \pm 1.8$ & $47.1 \pm 2.5$ & $38.3 \pm 1.5$ & $35.1 \pm 0.5$ & $29.5 \pm 1.6$ & $28.7 \pm 0.8$ & 0.001 \\
\hline Group & BCVA (log MAR) & $0.34 \pm 0.32$ & $0.41 \pm 0.09$ & $0.14 \pm 0.12$ & $0.31 \pm 0.9$ & $0.98 \pm 0.1$ & $0.48 \pm 0.34$ & 0.001 \\
\hline $\mathrm{B}$ & $\mathrm{IOP}(\mathrm{mm} \mathrm{Hg})$ & $47.34 \pm 1.8$ & $47.4 \pm 2.5$ & $42.34 \pm 1.5$ & $39.5 \pm 2.5$ & $34.4 \pm 1.7$ & $34.2 \pm 3.4$ & 0.11 \\
\hline
\end{tabular}

Data presented as mean $\pm \mathrm{SD}$, P-value $<0.05$ considered as significant 
Table 4: Serial changes for NVI during eight-month follow-up after intracameral Bevacizumab vs. sub-conjunctival Bevacizumab injection.

\begin{tabular}{lccccccc}
\hline NVI & Grade & Baseline NVI & First week & First Month & Third Months & Six Months & Eight Months \\
\hline Group A & 0 & $6(21.4 \%)$ & $11(39.3 \%)$ & $9(32.1 \%)$ & $8(28.6 \%)$ & $5(17.9 \%)$ & $6(21.4 \%)$ \\
& 1 & $3(10.7 \%)$ & $4(14.3 \%)$ & $3(10.7 \%)$ & $5(17.9 \%)$ & $6(21.4 \%)$ & $5(17.9 \%)$ \\
& 2 & $5(17.9 \%)$ & $4(14.3 \%)$ & $7(25.0 \%)$ & $4(14.3 \%)$ & $3(10.7 \%)$ & $10(35.7 \%)$ \\
& 3 & $8(28.6 \%)$ & $6(21.4 \%)$ & $5(17.9 \%)$ & $6(21.4 \%)$ & $8(28.6 \%)$ & $3(10.7 \%)$ \\
p-value & 4 & $6(21.4 \%)$ & $3(10.7 \%)$ & $4(14.3 \%)$ & $5(17.9 \%)$ & $6(21.4 \%)$ & $4(14.3 \%)$ \\
Group B & & $\mathbf{0 . 0 3 5}$ & $\mathbf{0 . 0 0 1}$ & $\mathbf{0 . 0 0 1}$ & $\mathbf{0 . 0 2 4}$ & $\mathbf{0 . 0 0 3}$ & $\mathbf{0 . 0 2}$ \\
& 1 & $0(0.0 \%)$ & $1(10.0 \%)$ & $1(10.0 \%)$ & $0(0.0 \%)$ & $2(20.0 \%)$ & $2(20.0 \%)$ \\
& 2 & $2(0.0 \%)$ & $3(30.0 \%)$ & $2(20.0 \%)$ & $3(30.0 \%)$ & $1(10.0 \%)$ & $3(30.0 \%)$ \\
& 3 & $3(30.0 \%)$ & $1(10.0 \%)$ & $1(10.0 \%)$ & $2(20.0 \%)$ & $2(20.0 \%)$ & $1(10.0 \%)$ \\
p-value & 4 & $5(50.0 \%)$ & $2(20.0 \%)$ & $3(30.0 \%)$ & $3(30.0 \%)$ & $2(20.0 \%)$ & $3(30.0 \%)$ \\
\hline
\end{tabular}

Data presented as n (\%)

$\mathrm{P}$-value $<0.05$ considered as significant

\section{DISCUSSION}

Although majority of NVG patients are effectively treated with PRP alone, still many necessitate additional maneuvers to control $\mathrm{IOP}^{12}$. Our results are consistent to Wolf A et al study, which showed fast and effective response to intracameral Bevacizumab injection in cases of $\mathrm{NVG}^{13}$. Bhagat PR et al reported that the effect of injection was initially acceptable but deteriorated after 8 weeks ${ }^{14}$. Contrary to that, we observed that intracameral route was effective in controlling IOP even at $8^{\text {th }}$ month. Some researchers have shown that sub-conjunctival Bevacizumab injection could be potentially useful as an initial treatment before laser or surgical treatment for NVG. However, recent studies have also shown that intracameral injections of Bevacizumab may be a better adjunct for the treatment of NVG. It results in regression of angle and iris neovascularization and the stabilization of $\mathrm{IOP}^{14}$. In our study, intracameral Bevacizumab was injected at the limbus close to NVI. Kim TW et al proposed that after subconjunctival Bevacizumab injections, macromolecules diffuse through the sclera directly into the iris ${ }^{15}$. Ghanem AA et al injected multiple injections of Bevacizumab in eyes with massive NVI that showed reappearance of NVI at $8^{\text {th }}$ month $^{16}$. However, in his study, transient IOP-lowering effects were seen in patients and the patients eventually required IOP-lowering surgery. Other studies showed that IOP and NVI rapidly decreased after intracameral Bevacizumab but to control new vessels a single intracameral injection was not enough ${ }^{2,17}$. In our study, the patients received 3.45 \pm 1.73 (group A) and $3.12 \pm 2.10$ (group B) injections, and $9(32.1 \%)$ and $4(40.0 \%)$ eyes received more than two injections in group A and B, respectively, similar to Ha JY et al study ${ }^{2}$.

Laser PRP is also an important therapy along with injection of Bevacizumab in NVG. As laser PRP is a confounding factor in clinical assessment of IOP, BCVA, and NVI, it was not given as a primary mode of therapy in our study, up to eight months of followup $^{18}$. Intracameral Bevacizumab was followed-up for eight months in our study and it was considered a safe procedure for corneal endothelium. Other studies evaluated the safety of intracameral Becacizumab for NVG and found no side effects on corneal endothelim ${ }^{19,20}$.

Limitation of our study was the small sample size. Furthermore, absence of control group (non-treated) or other forms of injections for comparison such as intravitreal or combined intracameral and intravitreal to determine the effect of intracameral injection was also the limitation of our study.

\section{CONCLUSION}

This study demonstrates that intracameral Bevacizumab significantly improves BCVA and controls IOP in neovascular glaucoma. However, subconjunctival Bevacizumab significantly improves BCVA but decrease in IOP is not statistically significant.

\section{Ethical Approval}

The study was approved by the Institutional review board/Ethical review board. 


\section{Conflict of Interest}

Authors declared no conflict of interest.

\section{Authors' Designation and Contribution}

Sharjeel Sultan; Assistant Professor: Concept and design, data analyses, manuscript writing, final review of manuscript.

Nisar A. Siyal; Associate Professor: Concept and design, Interpretation of data and final review of manuscript.

Nazish Waris; PhD Scholar: Interpretation of data, final review of manuscript.

A Rasheed Khokar; Professor: Concept and design, final review of manuscript.

\section{REFERENCES}

1. Shazly TA, Latina MA. Neovascular glaucoma: etiology, diagnosis and prognosis. In Seminars in ophthalmology. Taylor \& Francis, 2009; 24 (2): pp. 113-121.

2. Ha JY, Lee TH, Sung MS, Park SW. Efficacy and Safety of Intracameral Bevacizumab for Treatment of Neovascular Glaucoma. Korean J Ophthalmol. 2017; 31 (6): 538-47.

3. Sivak-Callcott JA, O'Day DM, Gass JD, Tsai JC. Evidence-based recommendations for the diagnosis and treatment of neovascular glaucoma. Ophthalmology, 2001; 108 (10): 1767-76.

4. Khattab A, Azmy E. Combined intracameral and intravitreal Bevacizumab injection in Neovascular Glaucoma. J Egypt Ophthalmol Soc. 2013; 106 (3): 117.

5. Li Z, Van Bergen T, Van de Veire S, Van de Vel I, Moreau H, Dewerchin M, et al. Inhibition of vascular endothelial growth factor reduces scar formation after glaucoma filtration surgery. Invest Ophthalmol. Vis. Sci. 2009; 50 (11): 5217-25.

6. Slabaugh M, Salim S. Use of Anti-VEGF Agents in Glaucoma Surgery. J Ophthalmol. 2017; 2017.

7. Wakabayashi T, Oshima Y, Sakaguchi H, Ikuno Y, Miki A, Gomi F, et al. Intravitreal Bevacizumab to treat iris neovascularization and neovascular glaucoma secondary to ischemic retinal diseases in 41 consecutive cases. Ophthalmology, 2008; 115 (9): 1571-80.

8. Chalam KV, Gupta SK, Grover S, Brar VS, Agarwal S. Intracameral Avastin dramatically resolves iris neovascularization and reverses neovascular glaucoma. Eur J ophthalmol. 2008; 18 (2): 255-62.

9. Yip VC, Yip LW, Laude A. Subconjunctival Bevacizumab for iris neovascularization. The Lancet Diabetes \& Endocrinology, 2014; 2 (6): 449-50.

10. Ehlers JP, Spirn MJ, Lam A, Sivalingam A, Samuel MA, Tasman W. Combination intravitreal Bevacizumab/panretinal photocoagulation versus panretinal photocoagulation alone in the treatment of neovascular glaucoma. Retina, 2008; 28 (5): 696-702.

11. Wakabayashi T, Oshima $\mathbf{Y}$, Sakaguchi H, Ikuno $\mathbf{Y}$, Miki A, Gomi $\mathbf{F}$ et al. Intravitreal Bevacizumab to treat iris neovascularization and neovascular glaucoma secondary to ischemic retinal diseases in 41 consecutive cases. Ophthalmology, 2008; 115: 1571-1580.

12. Wasik A, Song HF, Grimes A, Engelke C, Thomas A. Bevacizumab in conjunction with panretinal photocoagulation for neovascular glaucoma. Optometry-JOAOA. 2009; 80 (5): 243-8.

13. Wolf A, Von Jagow B, Ulbig M, Haritoglou C. Intracameral injection of Bevacizumab for the treatment of neovascular glaucoma. Ophthalmologica. 2011; 226 (2): 51-6.

14. Bhagat PR, Agrawal KU, Tandel D. Study of the effect of injection Bevacizumab through various routes in neovascular glaucoma. J curr glaucoma Prac. 2016; 10 (2): 39.

15. Kim TW, Lindsey JD, Aihara M, Anthony TL, Weinreb RN. Intraocular distribution of $70-\mathrm{kDa}$ dextran after subconjunctival injection in mice. Invest Ophthalmol Vis Sci. 2002; 43 (6): 1809-16.

16. Ghanem AA, El-Kannishy AM, El-Wehidy AS, ElAgamy AF. Intravitreal Bevacizumab (avastin) as an adjuvant treatment in cases of neovascular glaucoma. Middle East Afr J Ophthalmol. 2009; 16 (2): 75-79.

17. SooHoo JR, Seibold LK, Kahook MY. Recent advances in the management of neovascular glaucoma. In Seminars in ophthalmology. Taylor and Francis, 2013; 28 (3): 165-172.

18. Shin JP, Lee JW, Sohn BJ, Kim HK, Kim SY. In vivo corneal endothelial safety of intracameral Bevacizumab and effect in neovascular glaucoma combined with Ahmed valve implantation. J Glaucoma, 2009; 18 (8): 589-94.

19. Ha YA, Sung MS, Park SW. Efficacy and Safety of Intracameral Bevacizumab for Treatment of Neovascular Glaucoma. Korean J Ophthalmol. 2017; 31: 6. Doi:10.3341/kjo.2017.0017

20. Duch S, Buchacra O, Milla E, Andreu D, Tellez J. Intracameral bevacizumab (Avastin) for neovascular glaucoma: a pilot study in 6 patients. J Glaucoma, 2009; 18 (2): 140-3. 